\title{
Monitoring the Level of Light Pollution and Its Impact on Astronomical Bodies Naked-Eye Visibility Range in Selected Areas in Malaysia Using Sky Quality Meter
}

\author{
M. S. Faid ${ }^{1, *}$, N. N. M. Shariff ${ }^{1}$, Z. S. Hamidi ${ }^{2}$, S. N. U. Sabri², \\ N. H. Zainol ${ }^{2}$, N. H. Husien ${ }^{2}$ and M. O. Ali $^{2}$ \\ ${ }^{1}$ Academy of Contemporary Islamic Studies, Universiti Teknologi MARA, \\ Shah Alam, Selangor, Malaysia \\ ${ }^{2}$ Faculty of Applied Sciences, Universiti Teknologi MARA, \\ Shah Alam, Selangor, Malaysia \\ E-mail:msyazwanfaid@gmail.com; nur.nafhatun.ms@gmail.com; \\ zetysh@salam.uitm.edu.my; sitinurumairah@yahoo.com; \\ hidayahnur153@yahoo.com; hazwani_husien21@yahoo.com; \\ marhanaomarali@gmail.com \\ *Corresponding Author
}

Received 20 October 2016; Accepted 21 November 2016; Publication 8 December 2016

\begin{abstract}
Light pollution is an anthropogenic by-product of modern civilization and heavy economical activity, sourced from artificial light. In addition of its detrimental impact on human and ecology, light pollution brightens the night sky, limiting the range of visible astronomical bodies detected by naked-eye. Since it is becoming a global concern for astronomers, the level of light pollution needs to be monitored to study its mark on the astronomical data. Using Sky Quality Meter in the period of 5 months, we investigated the links between city population and its vicinity from the city center towards the profile of the night sky and the limiting magnitude of the naked eye. We eliminate the data factored by clouds and moon brightness on account of it has an adverse effect on sky brightness that could disrupt research on light pollution.
\end{abstract}

Journal of Industrial Engineering and Management Science, Vol. 1, 1-18.

doi: 10.13052/jiems2446-1822.2016.007

(c) 2016 River Publishers. All rights reserved. 
From the result, we can see population and location distance from the city as major variables of light pollution, as Kuala Lumpur, a city center sky is 5 times brighter than Teluk Kemang, a suburban sky. Some recommendation in reducing the effect of light pollution will be also discussed.

Keywords: Anthropogenic pollution, Light pollution, Population, Night sky brightness, Limiting magnitude.

\section{Introduction}

One of the massive downfalls of the modern civilization is the alteration of the natural environment, which include ambient light alteration in the night sky. The man-made light, or artificial light produces a sky glow, that scattered vertically, then returned back into our sky by the atmosphere making the sky brighter and disrupts the suppose night sky ambient. This phenomenon classified as one the human pollution towards the environment and it is called light pollution [1].

Increase in human population density in a certain location parallels with growth in economic and social infrastructure. However, this unstoppable economic growth and population development crops a massive light output through their street light and giant building spotlight that is directly proportional to the light pollution [2]. This trends keeps deteriorating, without people realizing it could damage the environment and the health of living things [3]. The truth is people find other issue more important although they concerned about the environment [4].

Naturally, human need a steady cycle of day and night hours throughout their life. The exposure of the artificial light imitates the sun brightness that disrupt the efficacy of melatonin in phase shifting circadian rhythms [5]. This disruption can cause widespread interruption of multiple body systems, resulting in serious medical consequences for individuals, such as bad job performance, increase in weight and even as bad as cancer [6].

Besides human, the light pollution can also affect animal. Throughout the synodic month, the night sky brightness is shaped by rhythmical shift of celestial object, namely moon. The night sky brightness varies from highest when the full moon and lowest at the new moon. Animal, bug, and all other living things acclimatize their life activity and cycle according to the synodic month cycle. Unfortunately, when monthly periods of sky brightness is interfered by artificial light, it hampers their harmonious life cycle [1]. The nightly routine of insects [7], birds [8] and turtles [9] is threatened as 


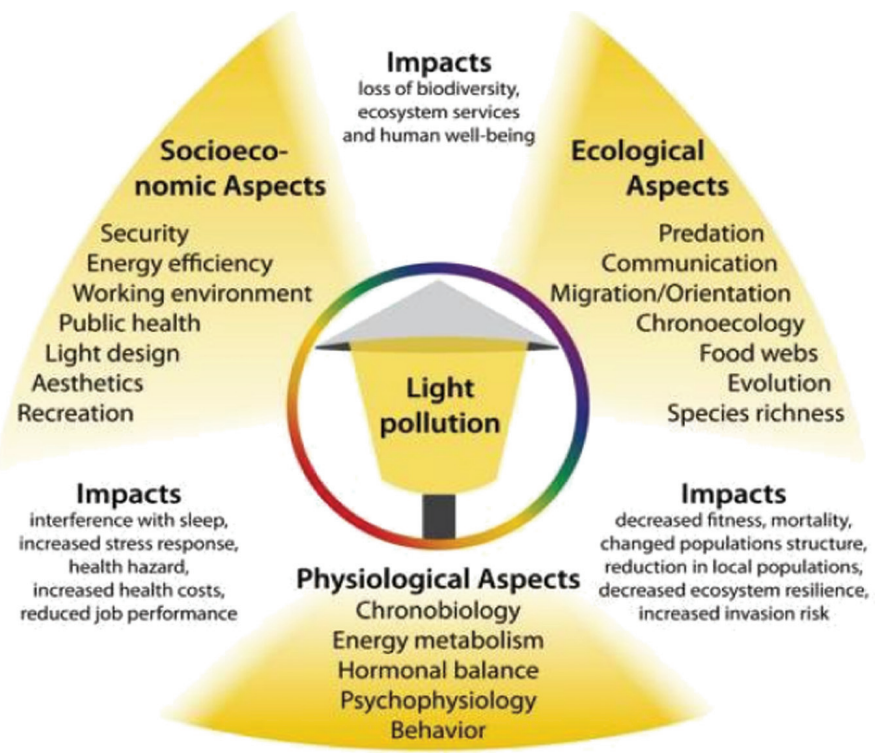

Figure 1 The effect of light pollution on living organisms [10].

it distorts their nocturnal nature [10], encompassing from foraging, mating, hatching and night navigation [11].

In terms of astronomy, the ground-observable astronomical bodies in the sky are determined by the contrast of these bodies with the night sky brightness [12]. The human eye has a certain contrast threshold [13] in detecting a dim celestial object in the sky [14]. The detection of celestial object on a certain night sky is quantified as Bortle scale [15], which believed to be application of knoll experiment. A highly polluted sky with low magnitude of sky brightness will lower the amount of celestial object visible to both naked and optical aid observation [16]. This make light pollution is the major concerns of astronomers considering its effect on ground based observation especially on optical and radio observation [17]. Therefore, it is an utmost importance to monitor the light pollution level to stress out its mark on astronomical data. According to the Garstang [18], the night sky brightness varies from one location to another location, depends on the element of population, economic activity and location distance from the nucleus of the population. A lowly populated area has a high viewing chance of multiple astronomical bodies compared to the heavily dense area [19]. Concerning about this problem, we examined the character of night sky brightness in selected areas in Malaysia. The purpose of the examination is to study the magnitude of sky brightness 
from different location profiles and to determine the number of celestial objects in the spectrum of naked eye visibility in respect to the locations. Since the zenith sky brightness signify the level of light pollution at that particular location [20], we can see the pattern of light pollution from two different location profile.

\section{Methodology}

\subsection{Instrument}

In this study, we will use SQM to determine the sky brightness of the night sky. The Sky Quality Meter (SQM) is a pocket device, to evaluate the sky brightness in the unit of $\mathrm{mag} / \mathrm{sec}^{2}$ developed by Unihedron. SQM use a light intensity to frequency detector, which then convert the output in digital LED reading. The sensor is covered by a near-infrared blocking filter to make sure the brightness reading is on the visible wavelength spectrum.

$$
f_{o}=F d+(R e)(E e)
$$

Where

Fo is the output frequency,

Fd is the output frequency for dark condition

$\mathrm{Re}$ is the device responsivity for a given wavelength of light given in $\mathrm{kHz} /\left(\mu \mathrm{W} / \mathrm{cm}^{2}\right)$

Ee is the incident irradiance in $\mu \mathrm{W} / \mathrm{cm}^{2}$

The output frequency is then converted into magnitude in the mean of formula

$$
m=-5 / 2(\log (f v / J y))+8.9
$$

Where

Fv is the spectral flux density or output frequency

Jy is the constant unit of Jansky

\subsection{Site Survey}

In this study, we stationed the SQM in two locations that have different site profile in terms of population density and its vicinity from the city center. These locations are classified as urban and suburban site, named Kuala Lumpur and Teluk Kemang respectively, and been pinpointed on the map by white mark. Figure 2 demonstrates the radiance map layered with population, courtesy 


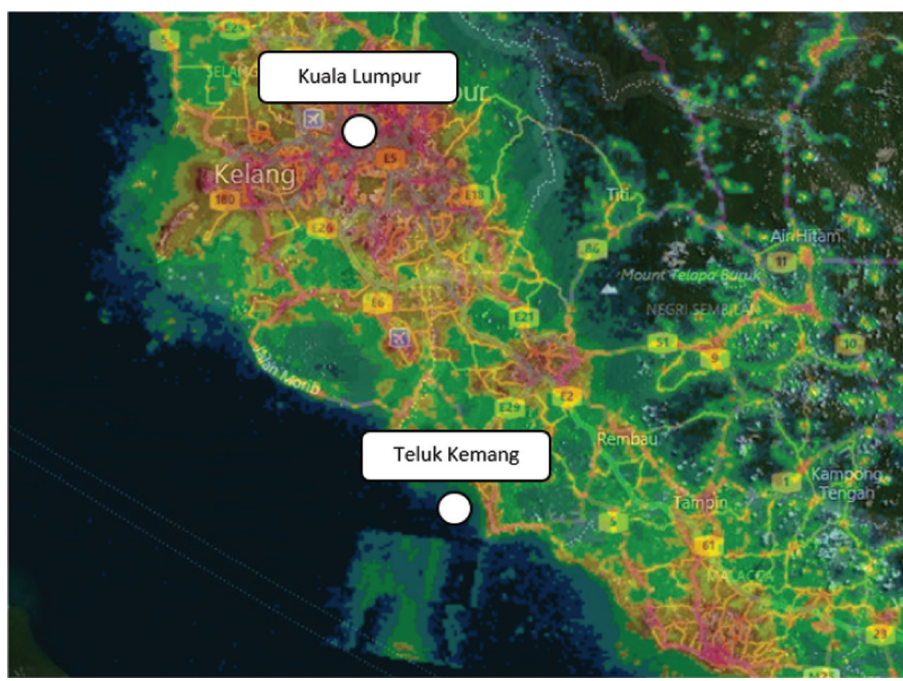

Figure 2 Irradiance mapping of Kuala Lumpur and Teluk Kemang.

of Jurij Stare ${ }^{1}$ which is from night time radiance composite images using Visible Infrared Imaging Radiometer Suite (VIIRS) Day/Night Band (DNB) produced by the Earth Observation Group, NOAA National Geophysical Data Centre. As you can see from the map, Kuala Lumpur is located at the center of the city, with a population of 1,674, 621 people in an area of $242.7 \mathrm{~km}^{2}$, meaning it has the density of $6900 \mathrm{inh} / \mathrm{km}^{2}$. While Teluk Kemang is located just at the $4 \mathrm{~km}$ from the city center Port Dickson, with a population of $115361 \mathrm{in}$ an area of $575.76 \mathrm{~km}^{2}$, indicates it has the density of $200.4 \mathrm{inh} / \mathrm{km}^{2}$. To monitor the overall light pollution, the measurement of night sky brightness is taken in the period of 5 months, from August to December.

Ten nights of hourly data are taken per month in Kuala Lumpur as heavy population traffic and close proximity to city suggest an inconsistency in sky magnitude thus longer hours of monitoring is needed for calibration to yield the actual night sky brightness data. On the other hand, single night per month is enough to represent the night sky brightness in Teluk Kemang, since it has a far distance from the city nucleus and dormant human activity.

Besides site distance from the city and its population density, there a few variables that could deviate the magnitude reading from the actual sky brightness. These variables occur naturally to any place in the world, namely the amount of cloud in the sky and the brightness of the Moon. Considering

\footnotetext{
${ }^{1}$ www.lightpollutionmap.info
} 
Malaysia climatology and the moon brightness [21], we expected the data to be fluctuated throughout measurement period, however, this data can be calibrated with a series of step.

\subsection{The Sky Brightness Fluctuation from Cloud Cover Amount}

One of the important aspects that could affect the sky brightness is the amount of cloud cover. In the case of Malaysia, the magnitude inconsistency of sky brightness is the result of the natural climatology of cloud in Malaysia which have a 65-95 percent amount of cloud cover in the sky throughout the year [22]. An overcast sky has a massive impact on the brightness of the night sky ranging from 3 to 18 times darker than clear sky depending on the location profile [23].

The high reflectivity of cloud reduces the amount of incoming solar radiation absorbed by the Earth-atmosphere system by increasing the albedo. Henderson describes the relationship between cloud and radiation of the sky by [24]:

$$
N e t=S(1-a)-F
$$

Where the net is the net radiation at the top of the atmosphere, $\mathrm{S}$ is incoming solar radiation or artificial light, $\alpha$ is albedo of the earth-atmosphere, and F is the infrared emission of space by the system. This equation indicates that an increase of cloud amount, will increase the albedo, which in our cases the sky brightness. We implemented the Okta Scale to study the effect of the cloud amount to the brightness of the sky in Okta Scale in 8-point scale ranging from 0 (completely clear sky) to 8 (fully covered sky). A study by Kocifaj and Solano Lamphar simulate that distance plays an important part for night sky irradiance due to cloud cover [25], and since Teluk Kemang is far from the city center for its night sky to be effected by the cloud, we do not include the analysis of Teluk Kemang's Okta Scale.

\subsection{Effect of Moon Phase on Sky Brightness}

After the effect of the cloud, the Moon is the highest natural contributor of the sky brightness. The Moon's scattered radiation depends on its altitude and phases, where we calculate the elliptical coordinate from Jean Meeus algorithms [26] and the moon phase is calculated from Smith [27]. Jason formulated that the moon scattered radiation can influences the night sky brightness up to 7 magnitude difference [28] which when full moon at its maximum brightness. A moon phases more than 0.5 in has long hour regime 
in the night sky while the full moon (phases $>0.9$ ) is above the horizon all night. In this study, we will examine the magnitude reading of the night sky that has the lowest yield of sky brightness from average magnitude reading and eliminate the data that show a clear influence of moon brightness, when moon phase $>0.5$.

\subsection{Naked Eye Limiting Magnitude}

By eliminating the data affected by cloud cover and moon phases, we then can obtain to actual yield of night sky brightness on that particular location. The difference pattern of night sky brightness at both location is then determined and the naked-eye range of visible astronomical bodies. The determination of the visible celestial object by the naked eye is expressed in the log of the night sky brightness magnitude (m) with formula [29] derived from Knoll, where NELM is the naked eye limiting magnitude.

$$
\mathrm{NELM}=7.93-5 \times \log \left(10^{4.316-(\mathrm{m} / 5)}\right)+1
$$

From this formula we can predict the visible object in the sky theoretically in respect of the distinction of both site profiles. The prediction is based on the Bortle Scale theory, relevant to the location characteristic.

\section{Results}

\subsection{Light Pollution Data}

The trends of the sky brightness at both stations throughout August until December are shown in Table 1. Cloud and moonlight are the major factors for the fluctuation trend of the graph. Malaysia was struck by a massive haze by November and September but the effect of haze can be accounted as same as the effect of cloud cover. Both suburban and urban sites indicate a stable difference between both of them, with urban sky brightness is 2 to 4 magnitudes brighter relative to the suburban site, under the same month and the same meteorological conditions. At a glance, we can agree that the population and their artificial light play a major explanation of the difference in magnitude, evidently shows that it is the cause of light pollution.

Since August 2015 until December 2015, a total of 55 raw data from Teluk Kemang and Kuala Lumpur. Of the Sky Brightness data collected, 50 data came from urban station Kuala Lumpur, while the rest is from suburban station Teluk Kemang. Table 2 presents the combined statistic. The total data average 
Table 1 Sky brightness throughout 5 months

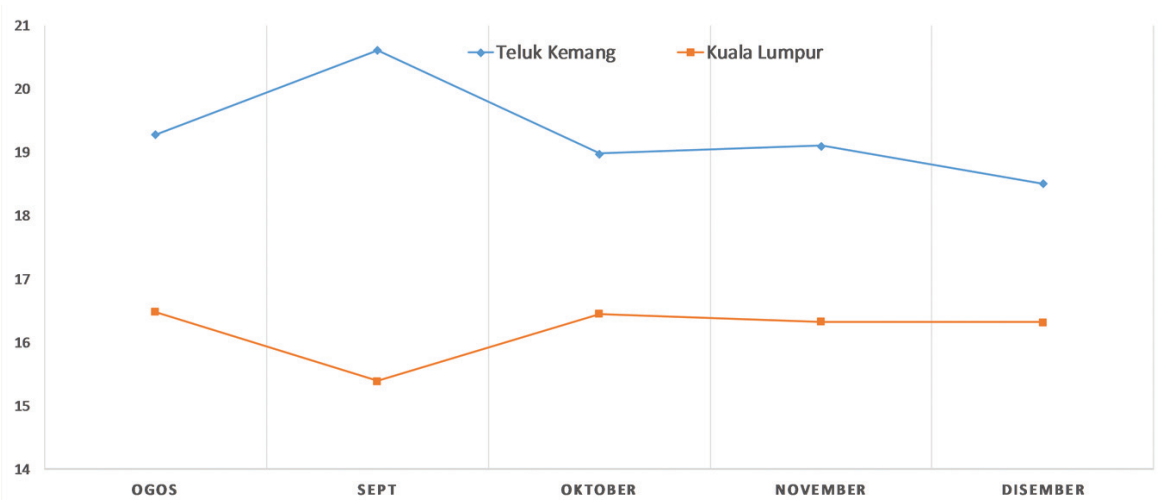

Table 2 Sky brightness data

\begin{tabular}{lccc}
\hline Location (Name) & Raw Data & Average & Standard Deviation \\
\hline Urban (KL) & 50 & 16.19 & 0.45 \\
Suburban (TK) & 5 & 19.30 & 0.78 \\
Total & 55 & 16.20 & 0.91 \\
\hline
\end{tabular}

is 16.2. As mentioned before, the sky brightness at the urban location show a lower average magnitude, therefore the sky brightness is higher or brighter than suburban location. The mean difference of magnitude from urban location Kuala Lumpur, with average 16.19 and suburban location Teluk Kemang, with average 19.30 is 3.11 .

This implies the urban location Kuala Lumpur is 17 times brighter than rural location Teluk Kemang. ${ }^{2}$ The combined histogram of Night Sky Brightness recorded in Figure 3. Since data from suburban location Teluk Kemang is a lot less than data from urban location Kuala Lumpur, it is being scaled so that it is comparable relatively. The largest difference of sky brightness in magnitude from urban location and suburban is $6 \mathrm{mag} / \mathrm{sec}^{2}$ or 251 brighter in observed luminosity. The highest frequency at urban location Kuala Lumpur is around $16 \mathrm{mag} / \mathrm{sec}^{2}$, while at suburban location Teluk Kemang is $19 \mathrm{mag} / \mathrm{sec}^{2}$. Both of these values are affected by the natural climatology of Malaysia that has a high amount of cloud cover in the sky throughout the year.

\footnotetext{
${ }^{2}$ Magnitude in brightness operates in $\log$ by the base of 2.512 . Therefore, the difference in mag, $x$, refers to flux ration of $2.512^{\mathrm{x}}$.
} 


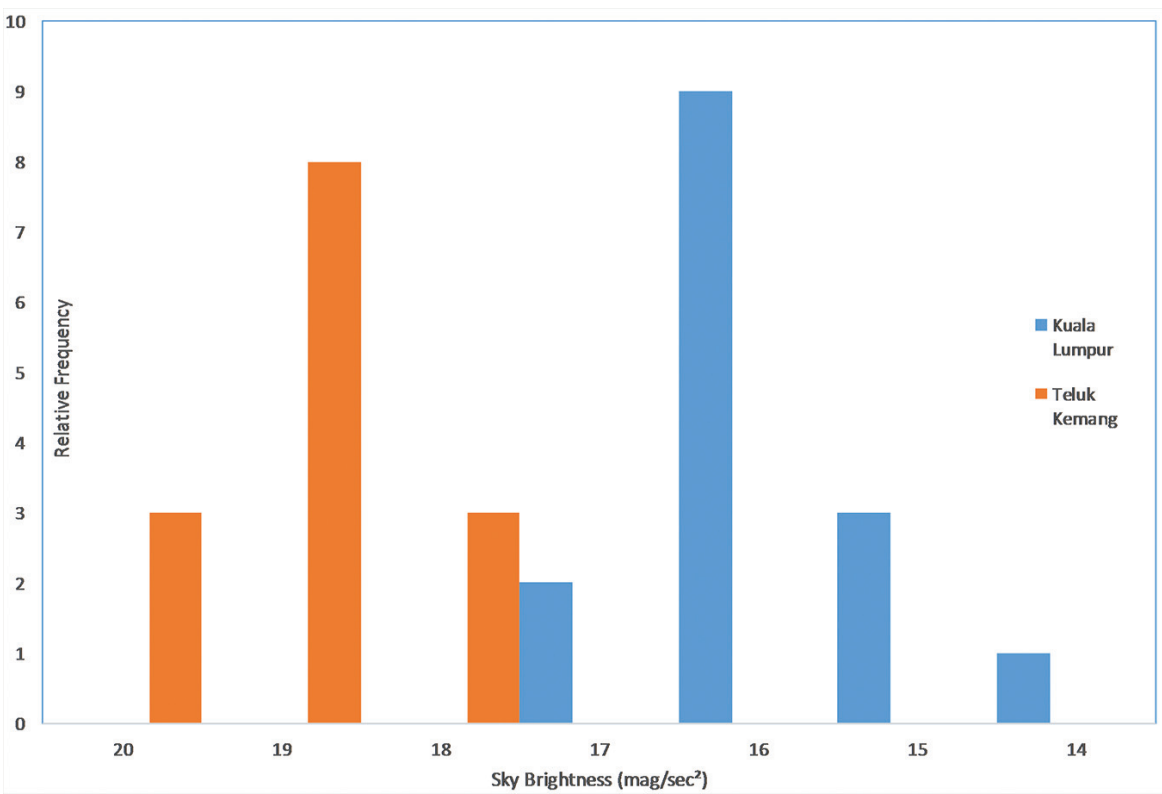

Figure 3 Relative frequency of brightness magnitude.

\subsection{Cloud Cover Effect}

The Okta relationship with night sky brightness is being portrayed is Table 3 . At lower magnitude, which less than 17, the data is densely distributed at 6-8 Okta Scale, while at magnitude higher than 17, we can see the data sparsely dispersed at 2-5 Okta Scale. The lowest value of sky brightness is 17.59 on the Okta Scale 2 or 31 percentage of cloud cover. A full clouds cover in the sky will contribute around 1.62 difference in sky brightness or 4.4 brighter

Table 3 Average magnitude over Okta scales

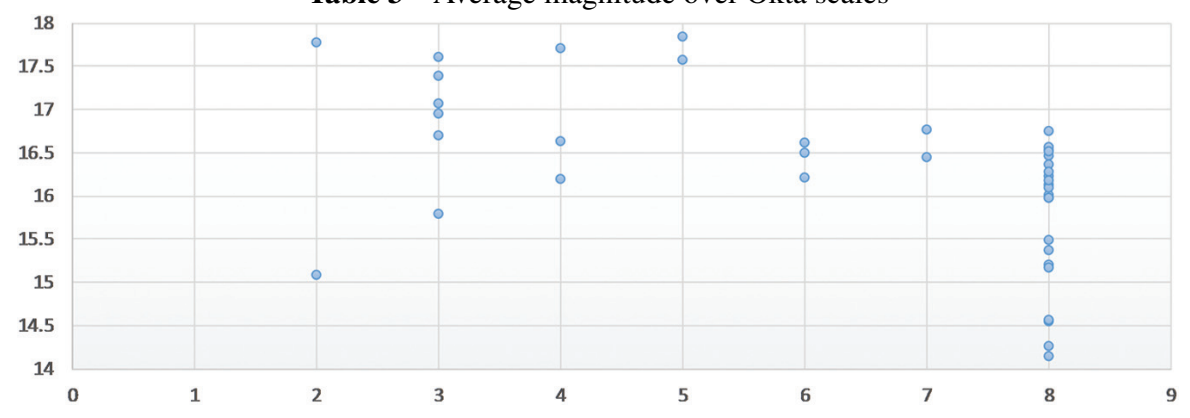


than cloudless sky. From a total of 55 data of sky brightness, a few data with magnitude less than 16 come to our attention.

\subsection{Moon Phase Effect}

The altitude of the moon during night depends on the phases of the moon. During the highest phases, or full moon, the moon altitude is always above the horizon throughout the night, making sky brightness data collection is not ideal. Table 4 exhibits that 4 of our data was clearly affected by the full moon, bringing a massive 2 magnitude difference in brightness from the lowest count of sky brightness, 17.59, or 6.5 times brighter. In early September until mid-November, Malaysia climatology is being stricken by terrible haze that obstructs optical depth of seeing. The aerosol particles contained in the haze scattered and absorb the artificial light making our sky brighter. This explains why data 5-10 have magnitude less than 16 even though it is not at the full moon. The effect of haze, at the maximum Air Pollution Index has contributed 3.52 differences of magnitude or 25 times brighter than the normal sky.

\subsection{Naked-Eye Limiting Magnitude}

By studying the natural phenomenon can that affect the sky brightness, at a normal percentage of cloud cover and neglecting the data at moon phases larger than 0.5, we can agree that 17.59 is the average brightness of the normal sky at urban location Kuala Lumpur and 19.28 is the average brightness of the normal sky is suburban location Teluk Kemang, portrayed in Table 5.

Table 4 Sky brightness \& moon phases

\begin{tabular}{llc}
\hline No. & Mag. & Moon Phases \\
\hline 1 & 15.97 & 0.99 \\
2 & 15.09 & 0.98 \\
3 & 15.16 & 0.97 \\
4 & 15.97 & 0.94 \\
5 & 15.78 & 0.27 \\
6 & 14.26 & 0.24 \\
7 & 14.55 & 0.16 \\
8 & 15.37 & 0.09 \\
9 & 14.55 & 0.06 \\
10 & 15.21 & 0.02 \\
\hline
\end{tabular}


Table 5 Magnitude of brightness and NELM

\begin{tabular}{|c|c|c|c|c|}
\hline Sites & $\begin{array}{l}\text { Magnitude } \\
\text { and Standard } \\
\text { Deviation }\end{array}$ & NELM & $\begin{array}{l}\text { Milky } \\
\text { Way }\end{array}$ & $\begin{array}{l}\text { Astronomical Object } \\
\text { and Constellations }\end{array}$ \\
\hline & & & $\begin{array}{l}\text { Not } \\
\text { Visible } \\
\text { at all }\end{array}$ & $\begin{array}{l}\text { The Pleiades Cluster is visible, } \\
\text { but very few other objects can } \\
\text { be detected. The constellation is } \\
\text { dimmer and lack of main star }\end{array}$ \\
\hline \multirow[t]{2}{*}{ Kuala Lumpur } & $17.59 / 0.92$ & 3.78 & & \\
\hline & & & $\begin{array}{l}\text { Not } \\
\text { Visible } \\
\text { at all }\end{array}$ & $\begin{array}{l}\text { The Pleiades Cluster is the only } \\
\text { object visible to all except for } \\
\text { experience observer. Only the } \\
\text { brightest constellation is } \\
\text { discernible and they are missing } \\
\text { star. }\end{array}$ \\
\hline Teluk Kemang & $19.28 / 0.70$ & 4.98 & & \\
\hline
\end{tabular}

This imply that the night sky in Kuala Lumpur is 5 times brighter than night sky in Teluk Kemang. The brightness of the sky can affect the limiting amount of celestial object brightness visible in that particular sky, or Naked Eye Limiting Magnitude (NELM).

\section{Discussion \& Conclusion}

After the elimination of natural contributors of night sky brightness, we can see the toll of artificial light in observing celestial objects in the sky. Kuala Lumpur sky, the site that has denser population and located in the city center is heavily polluted with magnitude value of $17.59 \mathrm{mag} / \mathrm{sec}^{2}$ and 3.78 nakedeye limiting magnitude, are 5 times brighter than Teluk Kemang which has brightness of $19.28 \mathrm{mag} / \mathrm{sec}^{2}$ and 4.98 naked-eye limiting magnitude.

The light pollution level in Teluk Kemang starting to worsen. Teluk Kemang has been a hot observation spot since years back and numbers of new moon observation records was achieved ${ }^{3}$.

But with increasing human activity in its nearby city Port Dickson, sparked by Port Dickson strategic location for tourism activity and all over the world, this location will be example of many other locations that may someday

\footnotetext{
${ }^{3}$ Youngest Moon Age and Smallest Elongation. For more info, see http://www.icoproject. org/record.html
} 
no longer viable for astronomical observation. The idea of maintaining the night sculpture in the sky may not be well accepted by the vast dimension of human society, since the impetus of humanity is driven by industrial expedience and economy, but we regard the idea of conserving mortal wellbeing and ecosystem stability is an idea shared by all. Attention concerning light pollution regulation and policy should be put at the highest priority since a rapid increase of artificial light every year endangering all livings things. Such simple initiative that can be implemented is by introducing the dark sky location specifically for astronomical observation and nocturnal animal activity, with a minimum distance of $7 \mathrm{~km}$ is good enough to conserve the night sky natural brightness. A more dramatic action is by proposing a total ban of man-made light at wavelength shorter than 540, since smaller wavelength in that spectrum has an inimical effect on human and animal health.

\section{Acknowledgment}

This work was supported by 600-RMI/RAGS 5/3 (121/2014), 600-RMI/ RACE 16/6/2 (4/2014) and 600-RMI/FRGS 5/3 (135/2014) FRGS/2/2014/ ST02/UITM/02/1 and Kementerian Pengajian Tinggi Malaysia. Special thanks to the Jurij Stare of www.lightpollutionmap.info and the NOAA National Geophysical Data Center for providing thematic map of night time irradiance. Also credit to Malaysia Department of Statistic for population density data and Permata Pintar Observatory UKM for atmospheric extinction observation and moon brightness data.

\section{References}

[1] Davies, T. W., Bennie, J., Inger, R., and Gaston, K. J. (2013). Artificial light alters natural regimes of night-time sky brightness. Sci. Rep. 3, 1722.

[2] Walker, M. F. (1977). The effects of urban lighting on the brightness of the night sky. Publ. Astron. Soc. Pac. 89, 405-409.

[3] Cinzano, P., and Elvidge, C. D. (2004). Night sky brightness at sites from DMSP-OLS satellite measurements. Mon. Not. R. Astron. Soc. 353, $1107-1116$.

[4] Shariff, N. N. M., Hamidi, Z. S., Musa, A. H., Osman, M. R., and Faid, M. S. (2015). Creating awareness on light pollution' (CALP) project as a platform in advancing secondary science education," in Proceedings of the International Conference of Education, Research and Innovation, Seville. 
[5] Burgess, H. J., Sharkey, K. M., and Eastman, C. I. (2002). Bright light, dark and melatonin can promote circadian adaptation in night shift workers. Sleep Med. Rev. 6, 407-420.

[6] Navara, K. J., and Nelson, R. J. (2007). The dark side of light at night: physiological, epidemiological, and ecological consequences. J. Pineal. Res. 43, 215-224.

[7] Frank, K. (2006). Effects of artificial night lighting on moths. Ecol. Cons. Art. Night Light. 2006, 305-344.

[8] Merkel, F. R., and Johansen, K. L. (2011). Light-induced bird strikes on vessels in Southwest Greenland. Mar. Pollut. Bull., 62, 2330-2336.

[9] Witherington, B. E., and Bjorndal, K. A. (1991). Influences of artificial lighting on the seaward orientation of hatchling loggerhead turtles Caretta caretta. Biol. Conserv. 55, 139-149.

[10] Hölker, F. Wolter, C., Perkin, E. K., and Tockner, K. (2010). Light pollution as a biodiversity threat. Trends Ecol. Evol. 25, 681-682.

[11] Kyba, C. C. M., Ruhtz, T., Fischer, J., and Hölker, F. (2011). Lunar skylight polarization signal polluted by urban lighting. J. Geophys. Res. Atmos. 116, 1-7.

[12] Schaefer, B. E. (1993). Astronomy and the limits of vision. Vistas Astron. $36,311-361$.

[13] Tousey, R., and Hulburt, E. O. (1948). The visibility of stars in the daylight sky. J. Opt. Soc. Am. 38, 886-896.

[14] Crumey, A. (2014). Human contrast threshold and astronomical visibility. Mon. Not. R. Astron. Soc. 442, 2600-2619.

[15] Bortle, J. E. (2001). Introducing the bortle dark-sky scale. Sky Telesc. 60, 126-129.

[16] Falchi, F., Cinzano, P., Duriscoe, D., Kyba, C. C. M., Elvidge, C. D., Baugh, K., et al. (2016). The new world atlas of artificial night sky brightness. Sci. Adv. 2:6.

[17] Hamidi, Z. S., Abidin, Z. Z., Ibrahim, Z. A., and Shariff, N. N. M. (2011). "Effect of light pollution on night sky limiting magnitude and sky quality in selected areas in Malaysia," in Proceedings of the 3rd International Symposium \& Exhibition in Sustainable Energy \& Environment (ISESEE) (Rome: IEEE) 233-235.

[18] Garstang, R. H. (1991). Light Pollution Modeling. Light Pollut. Radio Interf. Sp. Debris 17:56.

[19] Cinzano, P., Falchi, F., and Elvidge, C. D. (2000). Naked eye star visibility and limiting magnitude mapped from DMSP-OLS satellite data. Mon. Not. R. Astron. Soc. 323:15. 
[20] Cinzano, P., Falchi, F., and Elvidge, C. D. (2001). The first world atlas of the artificial night sky brightness. Mon. Not. R. Astron. Soc. 328, 689-707.

[21] Pun, C. S. J., So, C. W., and Wong, C. F. (2012). "The night sky monitoring network in hong kong," in Proceedings of the Light Pollution: Protecting Astronomical Sites and Increasing Global Awareness through Education.

[22] Engel-Cox, J. A., Nair, N. L., and Ford, J. L. (2012). Evaluation of solar and meteorological data relevant to solar energy technology performance in malaysia. J. Sustain. Energy Environ. 3, 115-124.

[23] Kyba, C. C. M., Tong, K. P., Bennie, J., Birriel, I., Birriel, J. J., Cool, A., et al. (2015). Worldwide variations in artificial skyglow. Sci. Rep. 5:8409.

[24] Henderson-Sellers, A., Hughes, N. A., and Wilson, M. (1987). Cloud cover archiving on a global scale: a discussion of principles. Am. Meteorol. Soc. Bull. 62, 1300-1307.

[25] Kocifaj, M., and Lamphar, H. A. S. (2014). Quantitative analysis of night skyglow amplification under cloudy conditions. Mon. Not. R. Astron. Soc. 443, 3665-3674.

[26] Meeus, J. (1991). Astronomical Algorithms, 2nd Edn. Virginia: Willmann-Bell.

[27] Smith, P. D. (2005). Practical Astronomy With Your Calculator. Cambridge: Cambridge University Press.

[28] Pun, C. S. J., So, C. W., Leung, W. Y., and Wong, C. F. (2014). Contributions of artificial lighting sources on light pollution in Hong Kong measured through a night sky brightness monitoring network. J. Quant. Spectrosc. Radiat. Transf. 139, 90-108.

[29] Knoll, H. A., Tousey, R., and Hulburt, E. O. (1946). Visual thresholds of steady point sources of light in fields of brightness from dark to daylight. J. Opt. Soc. Am. 36, 480-482. 


\section{Biographies}

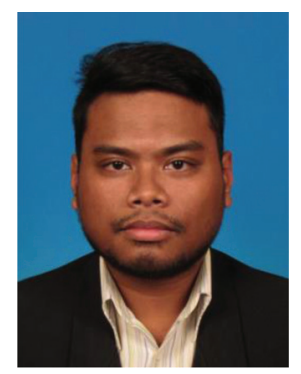

M. S. Faid is currently a master student at Universiti Teknologi MARA, Shah Alam Malaysia. Researching in algorithm for new moon visibility criteria. Interest in the study of light pollution and twilight sky brightness.

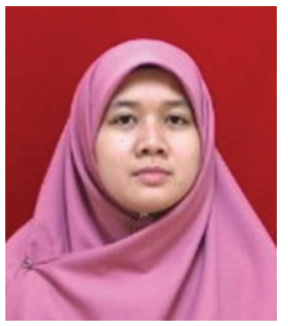

N. N. M. Shariff She is a senior lecturer at Academy of Contemporary Islamic Studies, Shah Alam. She obtained all her degrees from Universiti Malaya (UM) in Islamic Astronomy and Science \& Technology Studies. Currently she holds several positions as a Research Management Unit (RMU) coordinator and Malaysian Research Assessment (MyRA) Liaison Officer. She is one of editorial board for Journal of Contemporary Islamic Studies (JCIS), Senior Fellow of Centre for Human Rights and Advocacy (CENTHRA) and member of Malaysian Islamic Astronomy Society. Recently she is also appointed as associate fellow at Institute of Science (IOS). 


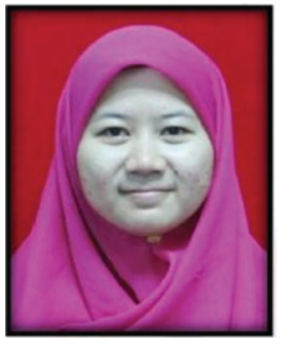

Z. S. Hamidi is currently a Senior Lecturer at Universiti Teknologi MARA, Shah Alam Malaysia. Involve in solar physics research and the project is under International Space Weather Initiative (ISWI) project under NASA project and published more than 150 publications. Also involves in others area of astronomy.

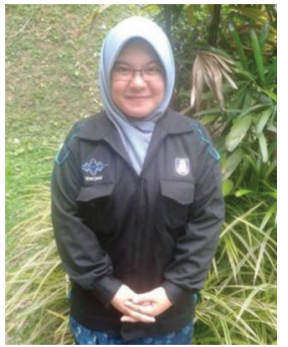

S. N. U. Sabri is currently a master student at Universiti Teknologi MARA, Shah Alam Malaysia. Involve in investigation on evaluation beta-gamma magnetic field on active region in solar radio burst.

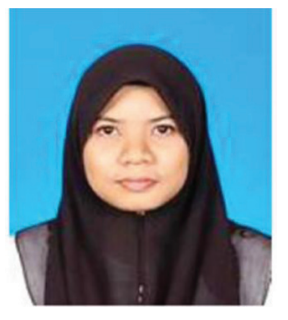

N. H. Zainol is currently a master student at Universiti Teknologi MARA, Shah Alam Malaysia. Study the Coronal Mass Ejection Based of Moreton Waves on the Characteristic of Solar Radio Burst Type 2. 


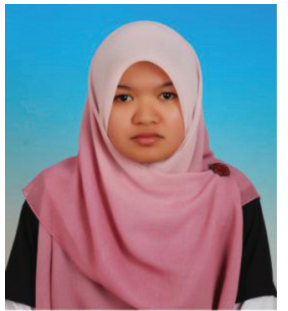

N. H. Husein is currently a master student at Universiti Teknologi MARA, Shah Alam Malaysia. Researching in solar radio burst type ii $n$ iii related with CME and solar flare.

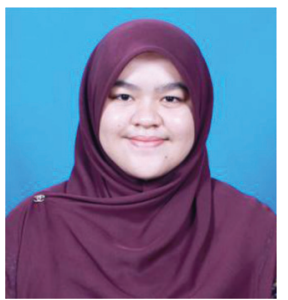

M. O. Ali is currently a master student at Universiti Teknologi MARA, Shah Alam Malaysia. Researching on solar radio burst type III and solar flare. 
